\title{
EL "CULTO JOVEN" Y SU RELACIÓN CON EL COMPROMISO CRISTIANO DE LOS JÓVENES DE LAS IGLESIAS ADVENTISTAS DEL SÉPTIMO DÍA DE ESPAÑA Y SANTA ISABEL DE LIMA METROPOLITANA, AÑO 2009
}

\author{
Esteban Silva, Felipe \\ Universidad Peruana Unión \\ felipeesteban@teologia.edu.pe
}

Fecha de recepción: Mayo 2013 Fecha de aceptación y versión final: Noviembre 2013

El objetivo del estudio es determinar la relación que existe entre el "Culto Joven" y el "Compromiso Cristiano" en los jóvenes de las iglesias adventistas de "España" y "Santa Isabel" de Lima Metropolitana, año 2009. Esta investigación es un estudio de tipo descriptivo correlacional-comparativo con un diseño no experimental, de corte transversal. Se utilizó la metodología de la encuesta con un instrumento validado para medir las variables en estudio a fin de conocer la relación que existe entre el "Culto Joven" y el "Compromiso Cristiano". El estudio demostró una correlación significativa entre el Culto Divino Tradicional donde participan los jóvenes junto con los adultos y el Compromiso Cristiano ( $r=.434 ; p=.000)$ en la iglesia Santa Isabel; así también el Culto Joven se relaciona significativamente con el Compromiso Cristiano ( $r=.312$; $p=.003)$ en la iglesia España, siendo estos componentes importantes en el desarrollo del compromiso cristiano.

Palabras clave: Culto joven, compromiso cristiano, jóvenes adventistas. 


\section{YOUTH WORSHIP SERVICE AND ITS RELATIONSHIP WITH THE CHRISTIAN COMMITMENT OF THE YOUTH IN THE SEVENTH DAY ADVENTIST CHURCHES OF ESPAÑA AND SANTA ISABEL OF METROPOLITAN LIMA, 2009}

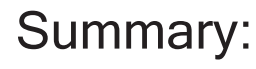

The objective of this study is to determine the relationship that exists between the "Youth Worship service" and the "Christian compromise" in the youth of the Seventh Day Adventists churches of "España" and "Santa Isabel" of Metropolitan Lima, 2009. This investigation is a descriptive correlational-comparative study, with a non-experimental design, and transversal. Questionnaires were used as a valid instrument to compare the variables in the study in order to find the existent relationship between the "Youth Worship Service" and the "Christian Commitment". The study/investigation demonstrated a significant correlation between the Traditional Youth Worship Service, in which the youth participated with the adults, and the Christian Commitment $(r=.434 ; p=.000)$ in the Santa Isabel church. The Youth Worship also relates significantly with the Christian Commitment $(r=.312 ; p=.003)$ in the Espana church, having these components being of great importance in the development of the Christian Commitment.

Keywords: Youth Worship, Christian Commitment, Adventist Youth. 


\section{Introducción}

Los jóvenes que ingresan a la Iglesia adventista y no se comprometen con ella, sino que después de bautizarse y participar en la iglesia por un tiempo, algunos de ellos se alejan, desconociéndose en forma objetiva los motivos de la misma. ${ }^{1}$

Algunos pastores adventistas indican que los adolescentes y jóvenes no encuentran una programación adecuada para

1 Entrevista a los pastores adventistas: Josué Llempén (secretario de la Misión Centro Oeste del Perú), Pr. Isaac Mansilla (exsecretario de la APC Norte y actual director del Departamento de Ministerio Personal de la Misión Centro Oeste del Perú), Pr. Enzo Chávez Idrogo (exdirector de Jóvenes de la Unión Peruana del Norte y actual presidente de la Misión Oeste del Perú), Pr. Edwin Regalado (exdirector de MIPES de la Unión Peruana del Norte y actual presidente de la Asociación Peruana Central Este), Pr. José Espinoza (director del Departamento de Jóvenes de la Asociación Peruana Central Sur), Pr. Daniel Romero Marín (director del Departamento Mayordomía y Asociación Ministerial de la Unión Peruana del Sur), con el hermano Walter Farfán (extesorero adjunto de la Unión Peruana del Norte, actual tesorero de la Misión Centro Oeste del Perú), Lima, 04 y 07 de febrero, 2011. ellos, la cual responda a las necesidades propias de su edad. ${ }^{2}$ La falta de programación adecuada para jóvenes, podría ser uno de los motivos de la falta de compromiso o alejamiento de la iglesia. ${ }^{3}$

Algunos miembros de iglesia opinaron debido a que algunos jóvenes asisten a la iglesia "obligados por sus padres", por esta razón ellos prestan atención a otros elementos en lugar de la predicación del culto de sábados de mañana. ${ }^{4}$

2 Entrevista a seis pastores adventistas. Josué Llempén (secretario de la Misión Centro Oeste del Perú), Pr. Isaac Mansilla (exsecretario de la APC Norte y actual director del departamento de Ministerio Personal de la Misión Centro Oeste del Perú), Pr. Enzo Chávez Idrogo (exdirector de Jóvenes de la Unión Peruana del Norte y actual presidente de la Misión Oeste del Perú), Pr. Edwin Regalado (exdirector de MIPES de la Unión Peruana del Norte y actual presidente de la Asociación Peruana Central Este), Pr. José Espinoza (director del Departamento de Jóvenes de la Asociación Peruana Central Sur), Pr. Daniel Romero Marín (director del Departamento Mayordomía y Asociación Ministerial de la Unión Peruana del Sur).

3 Entrevista con David Asmat y Ruth Carpio, miembros jóvenes de la IASD "España”, Lima, 01 de agosto, 2009.

4 Entrevista con Roy Carpio y Renzo 
El crecimiento de la Iglesia adventista en el Perú, que tuvo sus inicios en $1898,{ }^{5}$ como un grupo pequeño de miembros entre jóvenes y adultos, ${ }^{6}$ ha llegado al punto que en noviembre del 2011 se dividió la Asociación Peruana Central Norte, creando un tercer nuevo territorio misionero, el cual recibió el nombre de Misión Centro Oeste del Perú?.

Considerando que un gran porcentaje de los miembros son jóvenes, en la Asociación Peruana Central Norte, es decir el $40.75 \%$ y que únicamente en seis iglesias el culto joven está

Carranza, miembros jóvenes de la IASD "La Esperanza" de Vitarte y "Villa Unión" de la UPeU, Lima, 17 de septiembre, 2009.

5 Merling Alomía Bartra, Breve historia de la educación adventista en el Perú 18981996 (Lima: Ediciones Teológica, 1996), 2223.

6 G. H. Baber, "Chilean Mission", Review and Herald, 6 de junio de 1899, 363.

7 Misión Centro Oeste del Perú, Inauguran nuevas oficinas administrativas de la MICOP, http://micopadventistas.com/ (consultado: 02 de marzo, 2011).

8 Datos estadísticos recibidos por la secretaría de la Asociación Peruana Central Norte de la IASD, Lima, 16 de febrero, 2009. separado del culto divino de adultos los sábados de mañana ${ }^{9}$ es necesario verificar la influencia que esta práctica tiene en el compromiso cristiano de los jóvenes.

En una entrevista que se hizo a Jorge Zúñiga, coordinador del Departamento Pastoral Juvenil del Instituto Internacional de Evangelización a Fondo, menciona que los jóvenes y adolescentes no están encontrando respuesta a sus problemas existenciales ni respuestas a sus necesidades. ${ }^{10}$

Emilio Abdalá, profesor del Seminario Teológico Adventista de Bahía, Brasil, menciona que los líderes deben descubrir las necesidades de los jóvenes y adolescentes, a fin de ayudarlos a madurar; como dice el apóstol Pablo: "a la medida de la estatura de la plenitud de Cristo;..."

9 Entrevista vía telefónica con 47 pastores que atienden los distritos misioneros de la ciudad de Lima de la IASD de la Asociación Peruana Central Norte, 20 y 25 de febrero, 2010.

10 Jorge Zúñiga, ¿Cómo plantaremos las raíces?, http://www.obrerofiel.com/ contentprint-version.php $? \mathrm{a}=\& \mathrm{cn} \mathrm{t}=\mathrm{TkRNMg}==$ (consultado: 18 de febrero, 2008). 
(Ef 4:13,14), especialmente en este mundo marcado por la confusión, a fin de resistir su propaganda, y ayudarlos a crecer en dirección a la madurez espiritual con sentido de identidad y compromiso con la misión. ${ }^{11}$

En referencia al abandono que hacen algunos miembros de la iglesia, que en algún momento participaban activamente en ella; René Sand indica que es fundamentalmente un problema social, y no teológico, él dice que solo el $2 \%$ de la gente que deja la Iglesia lo hace porque no 30 cree en sus enseñanzas, y el 98\% restante abandona la fe porque tuvieron problemas de relaciones interpersonales. ${ }^{12}$

Tomando en cuenta las razones planteadas líneas arriba es necesario determinar, si el culto joven de sábados de mañana, está contribuyendo o no a que los jóvenes asuman su compromiso misionero con la Iglesia adventista. Se ha elegido las

11 Emilio Abdalá, "Una cuestión de prioridad", Ministerio Adventista, noviembre-diciembre 2008, 33.

12 René Sand, "Cierre la puerta de atrás", Ministerio Adventista, mayo-junio 2000, 27. iglesias adventistas de "España” y "Santa Isabel" perteneciente a la Asociación Peruana Central Norte de la ciudad de Lima Metropolitana, la primera porque tiene un programa donde los jóvenes participan de un culto joven los sábados de mañana; y la segunda porque tiene jóvenes que no participan del culto joven los sábados de mañana.

\section{Problema y objetivo general}

¿Cómo se relaciona el Culto Joven con el compromiso cristiano en los jóvenes adventistas de las iglesias España y Santa Isabel de la ciudad de Lima Metropolitana, 2009?

El objetivo de este estudio fue determinar la relación del "culto joven" y el compromiso cristiano en los jóvenes adventistas de las iglesias España y Santa Isabel de la ciudad de Lima Metropolitana, 2009. 


\section{Adoración}

El culto joven, ${ }^{13}$ es una de las principales actividades que se desarrolla todos los sábados de mañana en algunas iglesias adventistas del Perú, con la participación de jóvenes entre las edades de 15 a 35 años en un ambiente separado de los adultos. Dichas reuniones se realizan simultáneamente al desarrollo del culto religioso tradicional, donde adultos, jóvenes y niños se juntan para adorar de Dios. Generalmente ambos cultos se realizan en el horario de la ma-

13 Es pertinente aclarar que el término "Culto Joven" no aparece en el Manual de la Iglesia adventista como una terminología aplicada a alguna actividad o programa que el Ministerio Joven desarrolla, ni menos para designar la Sociedad de Jóvenes cuya programación se recomienda realizarse los viernes de noche o sábados de tarde. Asociación General de la IASD, Manual de la Iglesia (Buenos Aires: Asociación Casa Editora Sudamericana, 2000), 88. Según el investigador, el término "Culto Joven" es usado solamente para designar los dos programas denominados Escuela Sabática y Culto Divino desarrollados en ambientes separados de los adultos, todos los sábados de mañana en algunas iglesias adventistas de Lima Metropolitana y el mundo. ñana, cuya duración puede ser hasta el mediodía.

Esta práctica de desarrollar cultos en la Iglesia Adventista del Séptimo Día, está fundamentada en lo que las Sagradas Escrituras dice acerca de ello. Dios dice: "El que sacrifica alabanza me honrará" (Sal 50:23); además, Pedro refiere que la Iglesia es como "un sacerdocio santo, para ofrecer sacrificios espirituales, aceptables a Dios por medio de Jesucristo" (1 Pe 2:5), estos sacrificios espirituales del cual habla Pedro son la gloria que la Iglesia le da a Dios por medio de una respuesta de gratitud a su gracia, y esta adoración incluye la declaración de "las virtudes de aquel que os llamó de las tinieblas a su luz admirable" (v. 9).

Algunos ejemplos bíblicos acerca de la forma correcta de adorar, se puede encontrar en el libro de Levítico, donde Dios indica explícitamente a los levitas, músicos del templo, cantores, etc. lo que deben hacer en relación a este tema. Otro ejemplo se puede ver cuando Dios se 
manifiesta a Abraham y le ordena que sacrifique a Isaac su hijo como un acto de adoración a Él (Gn 22:1-19), cuya respuesta del adorador es la obediencia a Dios. La otra ocasión, es cuando Dios se presenta a Jacob en sueños, mencionándole las bendiciones que Él le va a dar, lo cual motiva al patriarca a adorar a Dios con mucho respeto y temor en ese lugar (Gn 28:10-22).

De otro lado, los cuatro primeros mandamientos de la Ley de Dios dadas a Moisés en el Sinaí, también refieren la ordenan32 za de adorar a Dios (Ex 20:3-11), el primero, por ejemplo, señala a Dios como el único que tiene derecho a la adoración suprema. El segundo prohíbe adorar a Dios por medio de imágenes. El tercero reclama reverencia para con el nombre de Dios y el cuarto dice que los que guardan el séptimo día demuestran que son verdaderos adoradores de Dios. ${ }^{14}$

Otra referencia bíblica que

14 Elena G. de White, Patriarcas $y$ profetas (Mountain View, California: Pacific Press Publishing Association, 1971), 313,315. señala la forma correcta de adoración a Dios, son los Salmos de alabanza, especialmente los salmos 95 al 100, y 145 al 150 donde habla de venir a Dios y postrarse ante Él y adorarlo porque se lo merece, y no solo el hombre, sino también los animales, naturaleza y todo lo creado. Isaías 6:1-8 tal vez sea uno de los más importantes en cuanto a modelo de adoración se refiere, ya que esta visión presenta a los ángeles adorando a Dios con grande reverencia, y a un hombre, Isaías, profundamente pasmado y temeroso ante impresionante visión del trono de Dios.

Jesús, en el diálogo con la mujer samaritana registrado en Jn 4:20-24, señala la importancia del cómo realizar una adoración a Dios, y no tanto por el lugar dónde hacerlo.

Y finalmente, cuando se lee el mensaje de los tres ángeles registrado en Ap 14:6-12, se dirige una invitación a todos los seres humanos para que adoren a Dios en los tiempos del fin, previo a la Segunda Venida de Jesús. 
La Biblia presenta una relación estrecha entre la palabra "culto" con los términos "adoración" y "liturgia". La primera de ellas proviene del griego koiné "Proskuneo" que significa reverenciar u homenajear y es usada unas 59 veces en el Nuevo Testamento para indicar el homenaje que se le rinde a una persona al postrarse a sus pies. En el Antiguo Testamento, el vocablo proviene del hebreo "Shachah" y es usado más de 170 veces para indicar adoración, el cual se traduce literalmente como inclinarse, caer delante, postrarse, arrodillarse. ${ }^{15}$

\section{Perspectivas de diversos autores acerca de la adoración}

La glorificación de Dios, refiere Dederen, se concentra en alabar y exaltar al Señor, aunque también tiene la intención de beneficiar a quienes le adoran (Heb 10:25). ${ }^{16}$

15 W. E. Vine, Expository Dictionary of Old and New Testament Words, Revell Co., New Jersey, 1981.

16 Raoul Dederen, "La doctrina de
De otro lado, Dom Eugenio Vandeur ha dicho, con mucho acierto, que "la adoración es un homenaje primordial, absoluto, tributado por la criatura a la divina Excelencia, cuyas grandezas confiesa juntamente con todos sus derechos soberanos sobre todo cuanto existe. Es el homenaje de la criatura racional al Dios tres veces Santo, que la saca de la nada, imprime en ella el sello de su propia Trinidad y se convierte luego en el Huésped divino del alma transformada por la gracia". ${ }^{17}$

Elena de White, también refiere que: "Cada corazón que es iluminado por la gracia de Dios es constreñido a inclinarse con inexpresable gratitud y adoración delante del Redentor por su sacrificio infinito". ${ }^{18}$

la iglesia”, en Teología: Fundamentos Bíblicos de nuestra fe, eds. Félix Cortés, Francesc X. Gelabert, José I. Pacheco (México D.F.: Gema Editores, 2007), 221, 222.

17 Citado en Francisco Lacueva, Espiritualidad trinitaria (Terrassa, Barcelona: Clie, 1983), 236.

18 Testimonios. 4: 461,462; en Biblioteca electrónica: Fundamentos de la Esperanza, CD-ROM, versión 1.0 (Miami: Folio VIP Electronic Publishing, 1992- 
Para W. T. Conner, la adoración es la razón de ser de la iglesia de Cristo, y debería estar en el corazón de todo lo que la iglesia hiciera. Agrega él, que la adoración es el resorte principal de toda la actividad de la iglesia. ${ }^{19}$

Todo esto concuerda con la revelación bíblica donde se enfatiza que la Iglesia existe "para la alabanza de su gloria" (Ef. 1:6). De esta forma, se podría decir que la Iglesia está llamada a rendir una adoración continua a Dios, que es camino hacia el crecimiento espiritual, tanto

34 personal como corporativo (Ro 12:1-2, 1P 2:9-10). Además, Conner agrega que no debiera adorarse solamente para mantener una actividad en la Iglesia, ya que esto estaría colocando la actividad como el asunto de primer orden y la adoración como secundaria. ${ }^{20}$

Infelizmente en estos últimos años se está experimentando un

1993). Folio e-book.

19 W. T. Conner, El Evangelio de la redención, trad. Lemuel C. Quarles (Texas: Casa Bautista de Publicaciones El Paso, sin fecha), 300.

20 W. T. Conner, 301. "desapego" a la Biblia como fundamento y guía, especialmente en relación a la forma de adorar a Dios. Puede ser algo inconsciente, pero es real. Es probable que el posmodernismo este ayudando a esta realidad. Se habla mucho de "experiencias", de "sentir", de "gozar", pero poco de la Biblia. Pareciera ser más importante la experiencia con Dios que el conocimiento de la Palabra.

Un análisis que C. Peter Wagner hiciera de la adoración en nuestro tiempo resalta que: "la adoración actual está conectada a tres fuentes importantes: 1) al sistema de amplificación de sonido; 2) al Espíritu Santo y 3) a la cultura contemporánea". ${ }^{21}$ La pregunta que entonces surge es: ¿Qué lugar se le da a la Biblia para cumplir el papel de guía en cuanto a la forma de adoración actual? Se cree que es necesario reconocer que la Biblia es la norma de fe y práctica de todo creyente, ya que a través de ella

21 C. Peter Wagner, ;Terremoto en la iglesia! (Nasville, TN: Editorial Betania, 2000), 158. 
se observa paradigmas o esquemas litúrgicos para la adoración, en los cuales resaltan principios aplicables al contexto y tiempo de cada ser humano.

Orlando Costas afirma que el culto es tan parte de los que adoran hoy a Dios como lo fue del antiguo Israel. Agrega él: "Así como la Ley y los Profetas no han sido destruidos con la aparición de Cristo, así tampoco desaparece la idea de un sistema de adoración pública. En Cristo ese sistema ha sido juzgado, recreado y transformado". ${ }^{22}$ En otras palabras, las formas, actitudes y sentimientos son básicos en la expresión del tributo que el hombre le debe a Dios y liturgia, culto y adoración tienen que ver con ellos, incluso "...hasta los cultos así mal llamados 'no litúrgicos' contienen elementos de este tipo. Todo parece ser dejado a la espontaneidad, pero la espontaneidad tiene ya sus canales fijos de expresión y forma". ${ }^{23}$

22 Orlando Costas, El culto en su perspectiva teológica (San José, Costa Rica: Seminario Bíblico Latinoamericano, 1971), 3.

23 Carlos A. Valle, Culto: crítica y búsqueda (Buenos Aires: Centro de Estudios
La Iglesia adventista de hoy no está ajena a enfrentar los nuevos paradigmas de adoración, sin embargo, es de esperar que durante este tiempo, se logre un equilibrio en los estilos y formas de adoración y descubrir que la riqueza de la adoración no está en quitar o sacar algo de una liturgia determinada, ni en imitaciones superficiales de liturgia. Aunque algunos jóvenes adventistas que asisten al culto divino de sábados de mañana exijan un cambio, porque consideran al culto como aburrido, según lo menciona Wann M. Fanwar. ${ }^{24}$

Cristianos Methopress, 1972), 22.

24 Wann M. Fanwar, El culto y los jóvenes en la Iglesia Adventista del Séptimo Día, http://www.portaladventista.com/Ministeriojovem/Jovens/EL\%20CULTO\%20 Y\%20LOS\%20JOVENES\%20EN\%20LA. doc (consultado: 01 de enero, 2008). Cabe resaltar lo que Fanwar menciona en este mismo artículo, acerca de la importancia de atender mejor al joven que asiste a la iglesia los sábados de mañana, él refiere lo siguiente: "A medida que preparamos a las personas para el retorno de Jesús, debiéramos encontrar el coraje que se demanda de los líderes para guiar a los miembros hacia una renovación en el culto. Si vamos a retener a nuestros jóvenes y presentarlos al Señor en su venida, debemos encontrar la visión para hacerlo. El tema que el culto 
Algunos líderes de iglesia han pensado solucionar esta situación, implementando un culto de adoración exclusivamente para jóvenes, el cual se desarrolla en otro salón, separados de los adultos.

Es bueno saber que muchos líderes de la Iglesia adventista están interesados en los miembros más jóvenes de la iglesia, las palabras escritas de Malcolm J. Allen, citadas en su libro ¿Conducción Divina o Presión Mundana?, en el capítulo titulado "La Reestructuración y la Reconstrucción del Ministerio Joven", resalta el acuerdo tomado el 9 de octubre de 1992 en el Concilio Anual de la Asociación General de la Iglesia Adventista del Séptimo Día cuya declaración apoya la idea de ayudar a los jóvenes adventistas en su desarrollo integral.

es percibido como "aburrido" por nuestros jóvenes debe ser tomado en cuenta. Hay una necesidad de experimentación, innovación y variedad, de lo contrario el culto será estático, irrelevante y 'aburrido'. Debemos hacer que nuestros cultos sean atractivos para nuestros jóvenes. Tenemos que ayudarles a entender que el culto es para ellos como lo es para los miembros adultos".
Esta declaración se resume de la siguiente manera:

1) La aceptación de los jóvenes como feligreses que participan plenamente de las actividades de la iglesia. 2) El nombramiento de especialistas en jóvenes en todos los niveles de la Iglesia. 3) El establecimiento de un ministerio joven organizado en cada iglesia. 4) Un cuádruple programa de atención a los jóvenes que incluyan reavivamiento, recuperación, evangelización y atención espiritual. 5) Autorización de un plan estratégico, con el fin de reconstruir y reedificar el ministerio joven. 6) La formación de un gabinete juvenil que acompañe al presidente en todos los niveles de organización de la Iglesia. ${ }^{25}$

Otra declaración importante para el desarrollo espiritual de los jóvenes adventistas es la que se votó en la reunión de San Luis realizada el año 2005 con motivo del $58^{\circ}$ Congreso de la Asociación General de la Iglesia Adventista del Séptimo Día, allí

25 Malcolm J. Allen, ¿Conducción divina o presión mundana? (Buenos Aires: Asociación Casa Editora Sudamericana, 1995), 57. 
se resaltó que "es tiempo de incluir a los jóvenes en el proceso de toma de decisiones, solo así sentirán que esta es su iglesia”, ${ }^{26}$ lo mismo piensa el pastor Gedeón Herrera, presidente de la Misión del Lago Titicaca en el Perú cuando dice que: "Los jóvenes deben tener el protagonismo en las iglesias, ya que ellos constituyen casi el cincuenta por ciento de nuestra membrecía en esta zona del país. Además, (agrega él), este protagonismo, ayudará al mismo joven en su compromiso con su iglesia y desarrollo como líder, y esto será posible, solo realizando cultos separados de los adultos". ${ }^{27}$

Esta preocupación por el fortalecimiento de la espiritualidad de los miembros más jóvenes, va en aumento dentro de la Iglesia adventista, y es que las estadísticas de fines del año 2004 y comienzos del 2005 muestran

26 Luis Gonzáles, "Una iglesia cada vez más plural”, Revista adventista, agosto 2005, 4.

27 Entrevista telefónica con el pastor Gedeón Herrera, presidente de la Misión del Lago Titicaca de la IASD en el Perú. (28/08/10) 9:21 p.m. que el setenta por ciento de sus miembros son menores de treinta años de edad, ${ }^{28}$ y según el informe estadístico de la Secretaría de la Iglesia Adventista del Séptimo Día en Sudamérica en el mes de setiembre del año 2010, refiere que la congregación está conformada principalmente por jóvenes y mujeres, siendo el 53,3\% el total de los jóvenes hasta 35 años, $24,6 \%$ son hombres y $28,7 \%$ son mujeres, ${ }^{29}$ ante esto, el pastor Erton Köhler, presidente de la IASD dijo: "Imaginábamos que esa era la realidad, pero ahora, con la comprobación estadística, podemos y vamos a trabajar con énfasis en esta realidad durante los próximos años. La manera de realizar evangelismo tendrá en cuenta el perfil de nuestros miembros". ${ }^{30}$

28 Luis Gonzáles, "Una iglesia cada vez más plural”, Revista Adventista, agosto 2005, 5.

29 Igreja Adventista Do Sétimo Día, La mayoría de los adventistas sudamericanos son jóvenes y mujeres, http://www.portaladventista.org/portal/asn---espa/3611-lamayoria-de-los-adventistas-sudamericanos-son-jovenes-y-mujeres (consultado: 07 de noviembre, 2010).

30 Igreja Adventista Do Sétimo Día, La mayoría de los adventistas sudamericanos son jóvenes y mujeres. 
Daniel Rode, un estudioso del crecimiento de iglesia, en su libro Crecimiento: Claves para Revolucionar su Iglesia destaca la formación y funcionamiento de este tipo de culto denominado culto joven en Argentina. Él dice:

En 1999, la junta directiva de la iglesia de la Universidad Adventista del Plata solicitó al pastor de jóvenes que organice cultos juveniles mensuales preparados para una mayor participación de los jóvenes de 12 a 18 años del secundario. La solicitud obedecía a que este grupo no tenía mayor participación en los cultos generales. Durante el 2000 y 2001, se organizaron estos cultos que comenzaron con unos 200 jóvenes, pero luego más de 700 participaban con alegría y entusiasmo en el Salón de los Pioneros. Por otro lado, en 2002 comenzó en forma simultánea el "culto juvenil" un "culto universitario" en el auditorio; ambos con amplia participación joven. Todo esto ha generado mayor adoración y nuevos ministerios misioneros... Más de 100 jóvenes están involucrados en los diferentes ministerios y en los grupos pequeños, que están ayudando a jóvenes díscolos.
Muchos padres expresan su satisfacción al ver a sus hijos involucrados en la iglesia. ${ }^{31}$

Esta misma forma de atención espiritual realizada por la mencionada universidad en favor de los jóvenes estudiantes, lo tiene la Universidad Adventista de Sahmyook de Seúl Corea del Sur, quienes implementan estrategias misioneras con el objetivo de ganar a jóvenes universitarios para la causa de Cristo. Una de ellas es ofrecer "cuatro tipos de cultos sabáticos: el estilo 'formal', para los miembros regulares, una adoración 'abierta' para los estudiantes de primer año, una adoración 'joven' donde se prepara a los estudiantes adventistas para el evangelismo". 32

Acerca de los orígenes de este tipo de cultos para jóvenes, no se ha encontrado un registro

31 Isabel y Daniel Rode, Crecimiento: claves para revolucionar su iglesia (Buenos Aires: Asociación Casa Editora Sudamericana, 2003), 77.

32 Sanglae Kim, Pescadores de hombres, http://spanish.adventistworld. or g / index.ph p o p tion $=\mathrm{com}_{-}$ content\&view=article\&id=39 (consultado: 09 de junio, 2010). 
histórico que hable sobre cómo apareció y cuál fue el primer lugar donde se celebró esta clase de culto, solo se puede decir que surge aproximadamente a fines del siglo anterior y comienzos del presente siglo, porque, revisando algunas otras páginas de Internet, se encontró un portal de la Iglesia luterana en Chile que presenta el desarrollo de los cultos religiosos para jóvenes dentro de sus iglesias desde $1997 .{ }^{33}$

Por otro lado, se encontró también otro portal de la Iglesia Wesleyana denominada "Brazos de amor" que tiene funcionando desde 1999 un culto especial para jóvenes con temas para ellos. $^{34}$ Pero, buscando documentación bibliográfica sobre el origen este tipo de culto joven celebrado los sábados de mañana en iglesias adventistas de la ciudad de Lima Metropolitana,

33 Iglesia Luterana de Chile, Cultos religiosos para jóvenes, http://www.luteranos.cl/cultos.html (consultado: 15 de febrero, 2005).

34 Iglesia Wesleyana, Brazos de amor, http://www.hablemosdefe.com/sec_iglesia.php (consultado: 15 de febrero, 2005). cabe mencionar que no se encontró información. Solamente se encontró referencias sobre adoración juvenil en el Manual del ministerio joven cuando describe acerca de la organización juvenil en la Iglesia Adventista de Norteamérica, allá por los años de 1879. Pero, únicamente, con el propósito de promover la obra misionera, de reunir dinero para comprar publicaciones misioneras, y trabajar a favor de la causa de la temperancia, ${ }^{35} \sin$ ningún propósito de funcionar como culto joven a realizarse los sábados de mañana.

Más adelante el Congreso de la Asociación General, realizado en Gland, Suiza, en la primavera de 1907, aprobó la formación de un departamento de jóvenes el cual se encargaría de velar por los objetivos de los jóvenes adventistas en el mundo entero. En 1911 algunos adultos interesados en la obra de los jóvenes organizaron clubes para los jóve-

35 Departamento de los Ministerios de la Iglesia, JA, de la Asociación General de la IASD, Manual del ministerio joven (Buenos Aires: Asociación Casa Editora Sudamericana, 1991), 17. 
nes que dieron origen a lo que hoy se conoce como el "Club de Conquistadores". 36

Como se ve, en la historia de programas y departamentos creados por la Iglesia adventista para atender a los jóvenes, no aparece este tipo de cultos como estrategia oficial para utilizarlo en la atención de los miembros en esta edad; además este tipo de cultos no está contemplado en el Manual de la Iglesia Adventista del Séptimo Día como una reunión autorizada.

Sin embargo, varios investigadores sobre el tema de crecimiento espiritual y compromiso cristiano en jóvenes que asisten a alguna iglesia cristiana, hacen notar su preocupación. Por ejemplo, el investigador católico Ozziel Nájera, dice que: "Sería necesario frente a estos escenarios presentes en la sociedad contemporánea plantearnos la posible revitalización de la fe cristiana, a través de nuevas y distintas experiencias de contac-

36 Departamento de los Ministerios de la Iglesia, JA, de la Asociación General de la IASD, Manual del ministerio joven, 18. to con lo sagrado en un contexto cultural que tiene como base el cristianismo, en su mayor parte católico", 37 aunque para José María Mardones no es tarea fácil enfrentar las novedades que trae el posmodernismo con su rechazo máximo de Dios y la religión ${ }^{38}$, ya que para él, "nos hallamos,..., ante una crisis cultural, mejor dicho, moral o, todavía con más precisión, crisis espiritual". 39

En esta misma línea de pensamiento, otro investigador llamado Horacio Martínez, hablando de este tema señala el cuidado que se debe tener al hacer estos cambios, para no permitir que la secularización influya a la fe, sino que "la secularización, en vez de influenciar a la fe, inste a la fe a un cambio de lenguaje y

37 Ozziel Nájera Espinosa. "Los nuevos imaginarios religiosos de los jóvenes". Revista de Antropología Experimental, no. 7 (2007), 147.

38 José María Mardones, Postmodernidad y cristianismo: llamados a dialogar con el fragmento (Santander: Sal Terrae, 1988), 81.

39 Mardones, Postmodernidad y conservadurismo: reflexiones sobre la fe y la cultura (Navarra: Verbo divino, 1991), 117. 
de expresión que traduzca para el hombre de hoy y de mañana la eterna Palabra de Dios trascendente y personal". ${ }^{40}$

Hanegraaff, hablando de los cuidados que una iglesia debe tener con la pureza de la fe cristiana al hacer algunos cambios en estos tiempos posmodernos dice:

Al haber perdido la capacidad de pensar bíblicamente, los cristianos posmodernos están siendo sistemáticamente transformados de ser agentes e iniciadores de cambio cultural a ser conformistas e imitadores. La cultura pop ejerce su atracción y los cristianos posmodernos están mordiendo el anzuelo. Como resultado, el modelo bíblico de la fe ha dado paso a una serie cada vez más extraña de modas y fórmulas. Dicho de otra manera, la pasión bíblica por ejercitar las disciplinas espirituales está cediendo terreno a las rápidas fórmulas de la teología de la fe..$^{41}$

40 Horacio Martínez Herrera, El compromiso social del cristiano (Bogotá: Editorial Pontificia Universidad Javeriana, 2005), $18,19$.

41 Hank Hanegraaff. Christianity in Crisis: $21^{\text {st }}$ Century (Tennessee: Grupo Nelson Inc., 2010), 10.
Carlos A. Forero añade que, en el mundo de los jóvenes posmodernos, juega un papel importante lo que está relacionado con la dimensión afectiva, y la labor pastoral que realizan los pastores de los juveniles. Deben tener en cuenta este aspecto, para saber discernir con las luces del espíritu, las estrategias más acertadas para tocar el corazón de los jóvenes. ${ }^{42}$

La adoración, entonces, no es solo un sistema o una experiencia. Es en realidad una profunda experiencia espiritual, en la cual funciona también la razón, y en este sentido, los jóvenes adventistas necesitan ser orientados.

Bien dijo el misionero Wedge Alman, en la conclusión de su mensaje en la clausura de un congreso misionero lo siguiente:

Sin compromiso, la Gran Comisión es solo una emoción que dura seis meses [...] Sin compromiso es cuestión de ir [...] y des-

42 Carlos A. Forero, "Posmodernidad y compromiso social de la juventud" (monografía para el seminario "Compromiso cristiano en el siglo XXI", Universidad de La Salle, Bogotá, diciembre de 2008), 21. 
pués regresar a mamá, a casa, al trabajo...Es necesario que despertemos y tomemos conciencia del hecho de que no estamos jugando a la guerra. Estamos literalmente en una verdadera lucha espiritual por la conquista de las almas que Cristo redimió cuando dio su vida en la cruz. Y así como Jesús se comprometió, cuando vino al mundo y murió para salvarnos, la extensión del Reino y los beneficios de su salvación jamás se lograrán a menos que los cristianos se conviertan en Discípulos, con mayúscula. Es decir, no de nombre, sino aceptando y viviendo lo que significa ser un seguidor de Jesús. Lo cual, indudablemente, implica un compromiso serio. ${ }^{43}$

\section{Elena de White y el compromiso cristiano}

\section{Hablando específicamente} de los miembros más jóvenes de la Iglesia adventista, Elena de White dice: "Tenemos un ejército de jóvenes hoy que puede hacer mucho si es debidamente dirigido y animado... Queremos

43 Oswald J. Smith, The Challenge of Missions (Gran Bretaña: STL Books, 1986), 104. que sean bendecidos por Dios. Queremos que participen en planes bien organizados para ayudar a otros jóvenes". ${ }^{44}$

Además dice ella que:

"Cuando los jóvenes dan su corazón a Dios, no cesa nuestra responsabilidad hacia ellos. Hay que interesarlos en la obra del Señor, e inducirlos a ver que él espera que ellos hagan algo para adelantar su causa. No es suficiente demostrar cuánto se necesita hacer, e instar a los jóvenes a hacer una parte. Hay que enseñarles a trabajar para el Maestro. Hay que prepararlos, disciplinarlos y educarlos en los mejores métodos de ganar almas para Cristo. Enséñeseles a tratar de una manera tranquila y modesta de ayudar a sus jóvenes compañeros. Expóngase en forma sistemática los diferentes ramos del esfuerzo misionero en que ellos puedan tomar parte, y déseles instrucción y ayuda. Así aprenderán a trabajar para Dios". 45

44 Elena de White, Testimonios para los ministros (Mountain View: Pacific Press Publishing Association, 1993), 32.

45 Elena de White, Obreros evangéli$\cos$ (Buenos Aires: Casa Editora Sudamericana, 1996), 222, 223. 
Pero ¿Será que todo este sistema de modificaciones y cambios ayuden a los jóvenes miembros de las diversas iglesias adventistas a asumir un compromiso cristiano? ¿Siendo que el compromiso cristiano que asume todo cristiano que asiste y participa en cualquier iglesia adventista, es la razón principal del crecimiento cualitativo y cuantitativo de la misma?

Pero ¿Qué significa que un creyente asuma un compromiso cristiano? El término "compromiso" en el idioma original, aparece en el griego como paratithe'mi, la cual significa "colocar al lado", "encargar", y se puede usar en el sentido de "confiar" según se registra en 1P 4:19. De otro lado, Pablo usa este término para aconsejar a sus maestros que debían transmitir a otros la verdad que habían recibido, él usa en $2 \mathrm{Ti}$ 1:14, el término paratheké la cual llega a ser entendida como un "compromiso", o "depósito" de fe para el día de Cristo (2Ti 1:12).

Para Elena de White compromiso del hombre con Dios, viene a ser "un pacto por medio del cual las partes contrastantes se obligan mutuamente al cumplimiento de ciertas condiciones. De este modo el instrumento humano entra en compromiso con Dios para cumplir las condiciones especificadas en su Palabra. Su conducta pone de manifiesto si respeta o no esas condiciones". ${ }^{46}$ Ella dice que: "El compromiso que caracteriza el pacto de los miembros de la iglesia es que cada uno camine en los pasos de Cristo, que cada uno tome sobre sí el yugo de Cristo y aprenda de Aquel que es manso y humilde de corazón". ${ }^{47}$

Entonces ¿Cómo lograr que un miembro de iglesia asuma un compromiso con Dios de acuerdo a lo que se acaba de ver? La respuesta se encuentra en la Biblia, ella afirma que la iglesia cristiana primitiva tenía un com-

46 Testimonios. 7: 30, 31; en Biblioteca electrónica: Fundamentos de la Esperanza, CD-ROM, versión 1.0 (Miami: Folio VIP Electronic Publishing, 1992-1993). Folio e-book.

47 Elena de White, Mensajes selectos, (EE.UU.: Pacific Press Publishing Association, 1993), 1:16. 
promiso con la obra de Dios en esta tierra, de predicar el evangelio de la salvación que es en Cristo Jesús, sin embargo, este compromiso asumido por ellos, dice la Palabra de Dios, era fruto del Espíritu Santo trabajando en el interior de estos cristianos. Era Él Quien dirigía a esta Iglesia en todas las decisiones y actos que ellos tomaban, era Él Quien les enseñaba todas las cosas y les recordaba todo lo que Jesús había dicho (Jn 14: 26). Es por medio de Él que los hombres nacen de nuevo, esto se puede ver en la conversación nocturna que tuvo Nicodemo con Jesús registrada en Jn. 3:1-13; es por el trabajo del Espíritu Santo que los primeros discípulos predicaron el evangelio con decisión y sin temor (Hch 2:1-42; 4:8-22; 4:31).

Elena de White refuerza esta idea diciendo que:

"Jesucristo, Dios mismo y los ángeles del cielo están interesados en este ministerio grande y sagrado. A los siervos del Omnipotente se les ha concedido el exaltado privilegio de manifestar el carácter divino mediante el compro- miso desinteresado en el esfuerzo por rescatar a los pecadores del abismo de la ruina a la cual han sido arrastrados. Cada ser humano que desea someterse será iluminado por el Espíritu Santo para poder participar en la realización del proyecto divinamente concebido. Cristo es la cabeza de su Iglesia y ella lo glorificará en la medida de que cada uno de sus integrantes participe en la operación de rescatar a los perdidos. Es por esto que los colaboradores humanos necesitan darle más lugar a la obra del Espíritu Santo a fin de poder trabajar más unidos, y así avanzar con la fortaleza que hay en un cuerpo unido de soldados." 48

De esta manera se entiende que para lograr que la iglesia asuma un compromiso cristiano, en primer lugar los líderes y miembros en general deben estar convencidos que este trabajo lo hace el Espíritu Santo. Así, ellos deben creer que, entregar todo el ser a Dios no es más que

48 Recibiréis Poder. 6 junio; en Biblioteca electrónica: Fundamentos de la Esperanza, CD-ROM, versión 1.0 (Miami: Folio VIP Electronic Publishing, 1992-1993). Folio e-book. 
un simple compromiso. Significa que se debe vivir y andar por la fe, sin ánimo de confiar ni de glorificar el propio yo, sino mirando a Jesús, Abogado, Autor y Consumador de la fe del cristiano, solo así estarán en condiciones de representarlo en palabra y acción. ${ }^{49}$

La promesa de Dios según White, es que todo aquel que se ofrece a sí mismo al Señor para servir, sin reservarse nada, se le da poder para lograr resultados inconmensurables. El Señor Dios se ha obligado por un eterno compromiso a suplir poder y gracia a todo aquel que sea santificado por medio de la obediencia a la verdad..$^{50}$ Dice ella "Que ninguno de los que por el bautismo se han comprometido a vivir para el servicio y la gloria de Dios, niegue su compromiso. Es necesario salvar al mundo y este pensamiento debe inducirnos a hacer mayores sacrificios

49 Ibíd., 25 de marzo.

50 Dios nos cuida. 12 agosto; en Biblioteca electrónica: Fundamentos de la Esperanza, CD-ROM, versión 1.0 (Miami: Folio VIP Electronic Publishing, 19921993). Folio e-book. y un trabajo más intenso en favor de los que están fuera del buen camino". ${ }^{11}$ Para esto, dice ella, que hay que mejorar los métodos; "no debe haber reglas fijas. Nuestra obra es progresiva, por lo tanto, hay que dejar lugar para que los métodos sean mejorados". 52

El 30 de setiembre de 1902, como abriendo las mentes a un nuevo siglo decía: "se concebirán nuevos medios para alcanzar los corazones. En esta obra se utilizarán algunos métodos que sean diferentes de los empleados en el pasado pero ninguna persona, a causa de esto, bloquee el camino mediante la crítica". ${ }^{53}$ Sin embargo, en el tema de la adaptación, ella dice que ello no debe comprometer los principios ${ }^{54} \mathrm{y}$ aclara que las

51 Testimonios selectos. 5: 34; en Biblioteca electrónica: Fundamentos de la Esperanza, CD-ROM, versión 1.0 (Miami: Folio VIP Electronic Publishing, 19921993). Folio e-book.

52 Elena de White, El evangelismo (Buenos Aires: ACES, 1975), 81.

53 Elena de White, Testimonios, t. 7 (Montain View, California: Pacific Press, 1953), 199, 200.

54 White, El evangelismo, 105. 
personas no deben adaptarse a los misioneros, sino son los misioneros quienes deben identificarse con las personas, alcanzarlas donde están y atender sus necesidades.

\section{Diseño metodológico}

El estudio es de tipo descriptivo correlacional - comparativo. Tiene un diseño no experimental, porque no se intervino las variables en estudio; ${ }^{55}$ de corte transversal, pues los datos se tomaron en un momento espe46 cífico.

\section{Población}

El estudio comprendió una población total de 165 miembros jóvenes de ambos sexos, cuyas edades fluctúen entre los 15 y 35 años de edad de las Iglesias adventistas del séptimo día de "Santa Isabel" y "España" de la Asociación Peruana Central Norte de la ciudad de Lima que

55 Roberto Hernández, Carlos Fernández y Pilar Baptista, Metodología de la investigación (Mexico: McGraw-Hill Interamericana, 2006), 209. asisten regularmente a los programas de culto de sábados de mañana.

Se ha tomado a 91 jóvenes de la Iglesia "España" quien representa a las iglesias que desarrollan programas de "Culto Joven" y 69 jóvenes de la Iglesia "Santa Isabel" que representan a las iglesias que desarrollan programas de culto "tradicional".

La investigación tiene dos hipótesis:

$\mathrm{H}_{\mathrm{i}}$ : Existe una relación positiva entre la asistencia al Culto Joven de sábados de mañana y el compromiso cristiano que asumen los jóvenes de las iglesias adventistas del séptimo día de "Santa Isabel" y "España" de la ciudad de Lima Metropolitana.

$\mathrm{H}_{0}$ : No existe relación entre la asistencia al culto joven de sábados de mañana y el compromiso cristiano que asumen los jóvenes de las 
iglesias adventistas del séptimo día de "Santa Isabel" y "España" de la ciudad de Lima Metropolitana.

La investigación contiene dos variables. Variable predictora, denominada Culto Joven; y variable criterio, denominada Compromiso Cristiano. El Culto Joven es un programa dirigido por jóvenes adventistas, para jóvenes que asisten a la iglesia el sábado de mañana, ya sea en el templo principal $\mathrm{y} / \mathrm{o}$ en forma paralela, en un ambiente aparte del templo; los cuales incluyen, la Escuela Sabática y el Culto Divino. Mientras que, Compromiso Cristiano es la calidad de vida espiritual en el aspecto cualitativo y cuantitativo de los jóvenes de las iglesias adventistas de la Asociación Peruana Central Norte de la ciudad de Lima Metropolitana.

Para recolectar la información se utilizó la técnica de la encuesta con su instrumento el cuestionario, el cual es un conjunto de preguntas dirigidas a la población objetivo, con el fin de conocer estados de opinión y/o hechos específicos acerca del programa de Culto Joven de sábado por la mañana y Culto Divino. El instrumento consta de tres secciones. La primera sección I corresponde a variables sociodemográficas con 11 preguntas. La sección II está conformada por 30 declaraciones con el objetivo de medir el Culto Joven de sábado por la mañana en las iglesias adventistas del séptimo día, divididas en dos grupos: Programa y ambiente físico de la Escuela Sabática (17 preguntas), desarrollo del Culto Divino y su ambiente físico (13 preguntas), y el Compromiso Cristiano con 22 preguntas.

Para validar el instrumento se solicitó el juicio de tres expertos los cuales fueron docentes y pastores de la IASD, y para la validación estadística se realizó una prueba piloto previa a la recolección de los datos determinanda la fiabilidad del instrumento en el coeficiente Alpha de Crombach. Obteniéndose los valores para el test global de 
0,797; para programa y ambiente físico del culto joven $0,635 \mathrm{y}$ para el compromiso cristiano 0,816 . Mostrando que el instrumento presenta consistencia interna.

Posteriormente se procedió a la validación del constructo; mediante el análisis factorial exploratorio de ítem por ítem del test en sus dos constructos: Culto Joven y Compromiso cristiano, el cual determinó la adecuación de los ítems en sus respectivos componentes, determinando los ítems a ser mejora48 dos o eliminados.

Los resultados muestran un $\mathrm{KMO}=0,431$, siendo la prueba de esfericidad de Bartlett significativa $(p=, 000)$, determinando la factibilidad de reducción de factores, la mayoría de los ítems saturan en su constructo verificándose la validez de criterio del instrumento a través del análisis factorial exploratorio con el método de varimax. Mostrando que el instrumento presenta validez de contenido y de criterio así como consistencia interna.

\section{Procedimiento de recolección de datos}

Para la recolección de datos se utilizó la técnica de la encuesta y el instrumento para recoger la información fue el cuestionario sobre el Culto Joven y el Compromiso Cristiano que el joven asume con su respectiva iglesia. Se trabajó con dos grupos. El primer grupo lo conformaron jóvenes que asisten a la Iglesia Adventista de "España" la cual ofrece un culto para jóvenes los sábados de mañana, y el segundo grupo estuvo conformado por jóvenes que asisten a la Iglesia Adventista de "Santa Isabel" la cual no ofrece un culto joven los sábados de mañana.

\section{Análisis de los datos}

Los datos recolectados se pasaron a una matriz de datos en el software estadístico SPSS 18. Para el análisis estadístico se utilizaron tablas y gráficos unidimensionales y bidimensionales, así como el uso de la prueba 
de independencia de criterios (chi-cuadrada) para medir la influencia de las variables sociodemográficas en el Culto Joven y Compromiso Cristiano. La prueba "r" de Pearson para determinar la correlación del "Culto Joven" y el "Compromiso Cristiano" y la prueba t para muestras independientes con el objeto de comparar los constructos en las iglesias de estudio.

\section{Resultados y discusión}

\section{Relación de las variables generales según tipo de iglesia}

Las frecuencias de las variables demográficas contrastando las iglesias en estudio y su relación a través de la prueba de independencia de criterios resultaron de la siguiente manera: Con respecto al sexo, el $57.1 \%$ de la Iglesia España y el 63.8\% de la Iglesia Santa Isabel son varones, no existiendo significancia estadística $(p=0.397)$, entre el sexo y el tipo de iglesia. Asimismo, se observa que en la Iglesia
España, la mayoría (77\%) son menores de 25 años, mientras que en la Iglesia Santa Isabel la mayoría $(42,6 \%)$ son mayores de 25 años, encontrándose significancia estadística $(\mathrm{p}=0.030)$ entre la edad y el tipo de iglesia. El $47.2 \%$ de los miembros de la Iglesia España tiene un grado de instrucción universitario, a diferencia de la Iglesia Santa Isabel que el $36.2 \%$ tiene un grado de instrucción universitario, no encontrándose significancia estadística $(p=0.310)$, entre el grado de instrucción y el tipo de iglesia. En cuanto a la institución donde estudiaron, el $42.7 \%$ de los jóvenes de la Iglesia España y el $18.8 .2 \%$ de la Iglesia Santa Isabel, estudiaron en una institución adventista, encontrándose significancia estadística $(p=0.001)$ entre la institución donde estudiaron y el tipo de iglesia. La mayoría (52.4\%) de los jóvenes de la Iglesia España estudian en la UPeU y el $30.4 \%$ de la Iglesia Santa Isabel, no encontrándose significancia estadística ( $\mathrm{p}=$ 0.076), entre la universidad 
donde estudia y el tipo de iglesia. Respecto a la ocupación, la mayoría (44.9\%) de los jóvenes de la Iglesia Santa Isabel trabajan de forma independiente o dependiente y solo el $25.5 \%$ en la Iglesia España, observándose significancia estadística $(\mathrm{p}=$ 0.022) entre la ocupación y el tipo de iglesia.

Con respecto a la influencia para adoptar la filiación de la IASD, el $55.7 \%$ de jóvenes de la Iglesia España, refieren que lo hizo por influencia de sus padres similar característica se 50 observa en la Iglesia Santa Isabel $(46.4 \%)$, no encontrándose significancia estadística $(\mathrm{p}=$ 0.422). En cuanto a los años de filiación a la IASD, se puede observar que el $46.1 \%$ de la Iglesia España y el 34.8\% de la Iglesia Santa Isabel tienen más de 9 años de permanencia en la iglesia, no encontrándose significancia estadística $(p=0.410)$, finalmente la mayoría de los jóvenes de la Iglesia Santa Isabel viven cerca a la iglesia $(81.2 \%)$ y solo el 46,6\% de la Iglesia España, siendo la relación entre el tiempo de distancia de su casa a la iglesia y el tipo de iglesia significativa $(p=0.000)$.

\section{Correlaciones del Compromiso Cristiano y el Culto Joven en la iglesia Santa Isabel}

En la iglesia donde se practica el culto joven (España), existe correlación positiva significativa entre el compromiso cristiano y el desarrollo del programa y el ambiente físico de la escuela sabática $(\mathrm{r}=.275 ; \mathrm{p}=.008)$, con el desarrollo del programa y el ambiente físico del culto divino $(\mathrm{r}=.246 ; \mathrm{p}=.019)$ y con el culto joven $(\mathrm{r}=.312 ; \mathrm{p}=.003)$. Con respecto al desarrollo del programa y el ambiente físico de la escuela sabática esta se correlaciona significativamente con el culto divino $(\mathrm{r}=.391 ; \mathrm{p}=.000)$ y con el culto joven $(\mathrm{r}=.927 ; \mathrm{p}=.000)$. El culto divino se correlaciona significativamente con el culto joven $(\mathrm{r}=.707 ; \mathrm{p}=.000)$. (ver tabla 1) 
El "culto joven" y su relación con el compromiso cristiano de los jóvenes de las iglesias adventista del séptimo día de España y Santa Isabel de Lima Metropolitana, año 2009

Tabla 1. Correlaciones del compromiso cristiano y el culto joven en la Iglesia España

\begin{tabular}{lccccc}
\hline & & & Escuela & Culto & Culto \\
& & Compromiso & Sabática & Divino & Joven \\
\hline \multirow{2}{*}{ Compromiso } & Sig. (bilateral) & 1 &, $275^{* *}$ &, $246^{*}$ &, $312^{* *}$ \\
& $\mathrm{~N}$ & 91 & .008 & .019 & .003 \\
& $\mathrm{R}$ & & 91 & 91 & 91 \\
Escuela & Sig. (bilateral) & 1 &, $391^{* *}$ &, $927^{* *}$ \\
Sabática & $\mathrm{N}$ & & .000 & .000 \\
& $\mathrm{R}$ & 91 & 91 & 91 \\
\hline \multirow{2}{*}{ Culto } & Sig. (bilateral) & & & 1 &, $707^{* *}$ \\
Divino & $\mathrm{N}$ & $\mathrm{R}$ & & & .000 \\
& $\mathrm{R}$ & & & & 91 \\
\hline
\end{tabular}

Culto Joven Sig. (bilateral)

$\mathrm{N}$

* La correlación es significativa al nivel 0,05 (bilateral).

** La correlación es significativa al nivel 0,01 (bilateral).

\section{Correlaciones del compromiso cristiano y el culto joven en la iglesia Santa Isabel}

En la iglesia donde no se practica el culto joven (Santa Isabel), existe correlación significativa entre el compromiso cristiano y el desarrollo del programa y el ambiente físico de la escuela sabática $(\mathrm{r}=.481 ; \mathrm{p}=.000)$ y con el culto joven $(\mathrm{r}=.434 ; \mathrm{p}=.000)$. El desarrollo del programa y el ambiente físico de la escuela sabática se correlaciona significativamente con el culto divino $(\mathrm{r}=.431 ; \mathrm{p}=.000)$ y con el culto joven $(r=.904 ; p=.000)$. Así también el desarrollo del programa y el ambiente físico del culto divino se correlaciona significativamente con el culto joven $(\mathrm{r}=.755 ; \mathrm{p}=.000)$, (ver tabla 2$)$. 
Tabla 2. Correlaciones para Escuela Sabática, Culto Divino, Culto Joven y Compromiso Cristiano de la Iglesia Sta. Isabel

\begin{tabular}{|c|c|c|c|c|c|}
\hline & & Compromiso & $\begin{array}{l}\text { Escuela } \\
\text { Sabática } \\
\end{array}$ & $\begin{array}{l}\text { Culto } \\
\text { Divino }\end{array}$ & $\begin{array}{l}\text { Culto } \\
\text { Joven }\end{array}$ \\
\hline \multirow[t]{3}{*}{ Compromiso } & $\mathrm{R}$ & 1 &, $481^{* *}$ & .205 &, $434^{* *}$ \\
\hline & Sig. (bilateral) & & .000 & .091 & .000 \\
\hline & $\mathrm{N}$ & 69 & 69 & 69 & 69 \\
\hline \multirow{3}{*}{$\begin{array}{l}\text { Escuela } \\
\text { Sabática }\end{array}$} & $\mathrm{R}$ & & 1 &, $431^{* *}$ & ,904** \\
\hline & Sig. (bilateral) & & & .000 & .000 \\
\hline & $\mathrm{N}$ & & 69 & 69 & 69 \\
\hline \multirow[t]{3}{*}{ Culto Divino } & $\mathrm{R}$ & & & 1 &, $775^{* *}$ \\
\hline & Sig. (bilateral) & & & & .000 \\
\hline & $\mathrm{N}$ & & & 69 & 69 \\
\hline
\end{tabular}

Sig. (bilateral)

$\mathrm{N}$

* La correlación es significativa al nivel 0,05 (bilateral).

** La correlación es significativa al nivel 0,01 (bilateral).

\section{Conclusiones}

De acuerdo a los resultados presentados en esta investigación sobre el Culto Joven y el Compromiso Cristiano de los Jóvenes de las iglesias adventista del séptimo día "España" y "Santa Isabel", se arriba a las siguientes conclusiones:
Respecto al objetivo general, se encuentra que el Culto Joven se relaciona significativamente con el compromiso cristiano de los jóvenes de las iglesias adventistas del séptimo día "España" y "Santa Isabel", en tal sentido, a mejor programa y ambiente fisico de culto joven, mayor compromiso cristiano. 
Respecto al primer objetivo específico, se encontró que en la Iglesia España los jóvenes participan activamente en la dirección del programa de Escuela Sabática, socializan en sus reuniones de grupos pequeños o programas de Escuela Sabática, participa en el repaso de la lección, exponen el Informe Misionero Mundial. En la Iglesia Santa Isabel se da mayor énfasis al uso de la Biblia y el folleto de Escuela Sabática así como la puntualidad al programa, observándose mayor énfasis en las doctrinas, en el Culto Divino entienden mejor el mensaje y satisface sus necesidades espirituales. En cuanto al ambiente físico en que se desarrolla el programa de Escuela Sabática y Culto Divino los jóvenes perciben mejor espacio, ventilación y comodidad en la Iglesia España que en la iglesia Santa Isabel.

Respecto al segundo objetivo específico, se observó que el compromiso cristiano en relación a la espiritualidad es superior en los jóvenes que pertenecen a la Iglesia Santa Isabel, sin embargo, en la Iglesia España se brindan más estudios bíblicos, se realiza actividades de visitación y ayuda al prójimo. El compromiso cristiano en relación a las actividades sociales es superior en algunos indicadores en los jóvenes que pertenecen a la Iglesia Santa Isabel, pero en la Iglesia España los jóvenes, en su mayoría, se abstienen de ir al cine, ir a celebraciones no cristianas y navegar en Internet en páginas prohibidas.

Respecto al tercer objetivo específico, se encontró que en la Iglesia donde se practica el culto joven (España), existe correlación positiva significativa entre el Compromiso Cristiano y el Culto Joven. En la iglesia donde se practica el Culto Joven tradicional (Santa Isabel), existe correlación significativa entre el Compromiso Cristiano y el Culto Joven. No se observa diferencia significativa entre el programa y ambiente físico de la Escuela Sabática, Culto Divino y Culto Joven en las iglesias que tienen programas de Culto Joven (España) vs Culto Joven tradicional (Santa Isabel), sin 
embargo, en el Compromiso Cristiano se observa diferencias, siendo el Compromiso Cristiano mayor en los jóvenes de la Iglesia Santa Isabel en relación a los de la Iglesia España.

\section{Recomendaciones}

Al finalizar el presente estudio, se presenta las siguientes recomendaciones:

1. Hacer una réplica de la presente investigación en grupos de jóvenes de otras iglesias para verificar el impacto que podrían tener otras variables además Compromiso Cristiano. Una de las otras variables podrían ser: el liderazgo del pastor.

2. Ampliar el tamaño de la muestra, a otras iglesias adventistas del séptimo día, para efectos de poder lograr mayor comprensión y generalización de los resultados.

3. Fomentar en las iglesias adventistas del séptimo día la práctica del Culto Joven mediante la instauración de un programa regular en el módulo semanal eclesiástico, siempre y cuando la iglesia sea grande en cantidad de miembros y también en infraestructura.

4. Concientizar a los líderes de la Iglesia Adventista del Séptimo Día sobre la necesidad de mejorar la programación tradicional de los cultos de sábados de mañana para que sean más atractivos para los jóvenes que asisten a las diversas iglesias de Lima Metropolitana, y de esta manera fortalecer más el compromiso cristiano de ellos.

5. Motivar el compromiso cristiano mediante programas desarrollados en formato juvenil en las iglesias adventistas de Lima Metropolitana, sin transgredir los principios bíblicos. 


\section{Bibliografía}

Abdala, Emilio, "Una cuestión de prioridad", Ministerio Adventista, noviembrediciembre 2008, 31-33.

Allen, Malcolm J. ¿Conducción divina o presión mundana? Buenos Aires: Asociación Casa Editora Sudamericana, 1995.

Asociación General de la Iglesia Adventista del Séptimo Día. Manual de la Iglesia. Buenos Aires: Asociación Casa Editora Sudamericana, 2000.

Baber, G.H."Chilean Mission”, Review and Herald, 6 de junio de 1899, 10-13.

Conner, W. T. El Evangelio de la redención, trad. Lemuel C. Quarles. Texas: Casa Bautista de Publicaciones El Paso, sin fecha.

Costas, Orlando El culto en su perspectiva teológica. San José: Seminario Bíblico Latinoamericano, 1971.

Dederen, Raoul "La Doctrina de la Iglesia”, en Teología: Fundamentos Bíblicos de Nuestra Fe. Editado por Félix Cortés, Francesc X. Gelabert, José I. Pacheco, México D.F.: GEMA EDITORES, 2007.

Departamento de los Ministerios de la Iglesia, JA, de la Asociación General de la IASD. Manual del ministerio joven. Buenos Aires: Asociación Casa Editora Sudamericana, 1991.

Doukhan, Lilianne. "¿Cuál es la manera apropiada de adorar a Dios?". Dialogo Universitario, vol. 15 nro. 3, 17-19.
Fanwar, Wann M., El culto y los jóvenes en la iglesia adventista del séptimo día, http://www.portaladventista.com/ Ministeriojovem/Jovens/EL\%20 CULTO\%20Y\%20LOS\%20JOVENES\%20EN\%20LA.doc. (consultado: 01 de enero, 2008).

Forero, Carlos A. "Posmodernidad y compromiso social de la juventud" (monografía para el seminario "Compromiso cristiano en el siglo XXI", Universidad de La Salle, Bogotá, diciembre de 2008.

Gonzáles, Luis. "Una iglesia cada vez más plural”, Revista Adventista, agosto 2005, 2-8.

Hanegraaff, Hank. Christianity in Crisis: $21^{\text {st }}$ Century. Tennessee: Grupo Nelson Inc., 2010.

Hernández Roberto, Carlos Fernández y Pilar Baptista. Metodología de la investigación. Mexico: McGraw-Hill Interamericana, 2006.

Iglesia Luterana de Chile, Cultos religiosos para jóvenes, http://www.luteranos.cl/ cultos. html (consultado: 15 de febrero, 2005).

Iglesia Wesleyana, Brazos de amor, http:// www.hablemosdefe.com/sec_iglesia. php (consultado: 15 de febrero, 2005). Igreja Adventista Do Sétimo Día, La mayoría de los adventistas sudamericanos son jóvenes y mujeres, Portal Adventista, http://www.portaladventista.org/ portal/asn--espa/3611-la-mayoria-delos-adventistas-sudamericanos-sonjovenes-y-mujeres (consultado: $07 \mathrm{de}$ noviembre, 2010). 
Lacueva, Francisco. Espiritualidad trinitaria. Terrassa: Clie, 1983.

Mardones, José María. Postmodernidad y cristianismo: llamados a dialogar con el fragmento. Santander: Sal Terrae, 1988.

Postmodernidad y conservadurismo: reflexiones sobre la fe y la cultura. Navarra: Verbo divino, 1991.

Nájera Espinosa, Ozziel. "Los nuevos imaginarios religiosos de los jóvenes". Revista de Antropología Experimental, N. ${ }^{\circ}$ 7 (2007): 143-151.

Rode, Isabel y Daniel Rode. Crecimiento: claves para revolucionar su iglesia. Buenos Aires: Asociación Casa Editora Sudamericana, 2003.

Sand, René. Cierre la puerta de atrás. Ministerio Adventista, mayo-junio, 2000, - Cierre la puerta de atrás. Ministerio Adventista, Setiembre-Octubre, 2000.

Smith,Oswald J. The Challenge of Missions. Gran Bretaña: STL Books, 1986.

Valle, Carlos A. Culto: crítica y búsqueda. Buenos Aires: Centro de Estudios Cristianos Methopress, 1972.

Vine,W. E. Expository Dictionary of Old and New Testament Words. New Jersey: Revell Co., 1981.

Wagner, Peter. Su iglesia puede crecer. Barcelona: CLIE, 1976.

, iTerremoto en la iglesia! Nasville, TN: Editorial Betania, 2000.

White, Elena G. de Patriarcas y profetas. Mountain View, California: Pacific Press Publishing Association, 1971.
. El evangelismo. Buenos Aires: ACES, 1975. . Mensajes selectos, t-1. EE.UU.: Pacific Press Publishing Association, 1993.

. Testimonios. 7; en Biblioteca electrónica: Fundamentos de la Esperanza, CD-ROM, versión 1.0 (Miami: Folio VIP Electronic Publishing, 19921993). Folio e-book.

. Recibiréis Poder. 6 junio; en Biblioteca electrónica: Fundamentos de la Esperanza, CD-ROM, versión 1.0 (Miami: Folio VIP Electronic Publishing, 1992-1993). Folio e-book.

, Dios nos cuida. 12 agosto; en Biblioteca electrónica: Fundamentos de la Esperanza, CD-ROM, versión 1.0 (Miami: Folio VIP Electronic Publishing, 1992-1993). Folio e-book.

, Testimonios selectos. 5; en Biblioteca electrónica: Fundamentos de la Esperanza, CD-ROM, versión 1.0 (Miami: Folio VIP Electronic Publishing, 1992-1993). Folio e-book.

, Testimonios. 4: 461,462; en Biblioteca electrónica: Fundamentos de la Esperanza, CD-ROM, versión 1.0 (Miami: Folio VIP Electronic Publishing, 1992-1993). Folio e-book.

, Testimonios para los ministros Mountain View: Pacific Press Publishing Association, 1993.

Zúñiga, Jorge ¿Cómo plantaremos las raíces? http://www.obrerofiel.com/contentprint-version.php? $\mathrm{a}=\& \mathrm{cnt}=\mathrm{TkRNMg}==$ (consultado: 18 de febrero, 2008). 